\title{
Desempenho da Gestão Pública: que variáveis compõem a aprovação popular em pequenos municípios?
}

Introdução

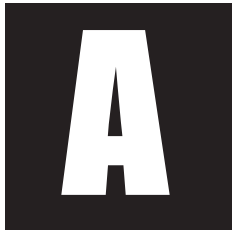

análise da Gestão Pública desenvolvida neste estudo, foi conduzida por um conjunto de incertezas e indefinições acerca dos fatores explicativos que se associam aos desempenhos das gestões municipais. Tais desempenhos que, aliás, têm apresentado padrões bastante diferenciados historicamente, sugerem agora análises mais ap rofundadas sobre suas peculiaridades, sobretudo após a descentralização em curso no País, nos últimos anos. Partindo desta perspectiva, o estudo propõe a idéia de que as diferenças encontradas no desempenho da gestão pública em municípios são definidas por alguns fatores específicos que se procura desvendar, expressando-se como determinantes do maior ou menor sucesso da gestão (LUBAM BO, 2000).

Não há dúvidas sobre o fato de que os municípios vêm assumindo maior autonomia e mais responsabilidades na provisão de bens e serviços públicos, ainda que de forma seletiva e na medida de suas possibilidades. Contudo algumas gestões, neste contexto, têm-se destacado mais que outras, sem que se tenha chegado a justificativas bastante convincentes para

* Doutora em Sociologia pela U niversidade Federal de Pernambuco. Pesquisadora da Fundação Joaquim N abuco e do Núcleo de 0 pinião e Políticas Públicas (N EPPU) no Depto. de Ciência Política da Universidade Federal de Pernambuco. D ocente no Mestrado de Gestão em Políticas Públicas para o Desenvolvimento do N ordeste, no Programa de Pós-graduação de Administração da UFPE. Brasil. 
Sociologias, Porto Alegre, ano 8, № 16, jul/dez 2006, p. 86-125

os seus desempenhos: se, de um lado, inexistem referências teóricas que proponham a correspondência entre os determinantes do êxito e uma dada tipologia de gestão, de outro, empiricamente, as análises têm, em geral, focalizado estudos de caso que acabam por atribuir forte significado aos contextos locais. M esmo assim, mantém-se uma forte polarização no debate público entre aqueles que apostam no fortalecimento dos governos locais como um processo positivo para a democracia e a eficiência alocativa do setor público, e aqueles que entendem que os municípios são a própria manifestação do clientelismo e da ineficiência, nos quais o aumento da autonomia local só favoreceria a ingovernabilidade.

O ra, após mais de duas décadas de vivência de descentralização, 0 debate sobre a temática não pode prescindir de análises que focalizem os governos locais sob o único aspecto capaz de revelar o impacto deste processo - o desempenho da gestão nas distintas localidades. São poucos, no entanto, os estudos sistemáticos so bre experiências descentralizadas, registrando-se, fundamentalmente, trabalhos que preferem abordar estudos de caso; ${ }^{1}$ exceções devem ser mencionadas para se incluírem estudos como 0 de ARRETCHE (1999 e 2004), que examina o processo de descentralização das políticas sociais e seus determinantes. A discussão sobre os constrangimentos e vicissitudes da descentralização sofre, assim, os efeitos da ausência de estudos que tomem por base um número significativo desses casos.

Diante desta lacuna (teórica e empírica), a hipótese aqui desenvolvida é a de que, embora as especificidades locais sejam limitadoras à existência de um modelo único de gestão exitosa, é possível identificar similaridades entre os fatores determinantes do bom desempenho em gestões, sobretudo quando os casos se referem a municípios de pequeno porte. Al-

1 FREY (1996) compara as experiências municipais de Curitiba e de Santos; SO UZA (1997) examina o caso de Salvador; CO UTO (1999) analisa a gestão de São Paulo; BAIO CCHI (2001) focaliza o ativismo e a participação política na experiência de Porto Alegre, ou FERN AN DES (2005), que estuda a gestão de capitais na década de 1990, comparando os casos Recife e Salvador. 
Sociologias, Porto Alegre, ano 8, № 16, jul/dez 2006, p. 86-125

guns desafios se colocaram, de partida, em conseqüência da adoção dessa hipótese: 1 . definir o que pode ser considerado uma gestão municipal satisfatória ou exitosa; 2 . selecionar fatores que supostamente se associam ao desempenho de uma gestão pública municipal; e 3. analisar o comportamento desses fatores, entre gestões que apresentam variados graus de êxito (e não apenas aquelas consideradas exitosas). Esta é a preocupação central deste estudo: investigar a associação existente entre o comportamento de alguns fatores específicos e a qualidade da gestão pública em municípios. A idéia é buscar identidades entre "boas" gestões, na perspectiva de elucidar algumas questões cotidianas como: Será que os melhores desempenhos registram-se onde se aliam um melhor padrão de desenvolvimento sócioeconômico e uma maior autonomia financeira? $\mathrm{O}$ u será que as condições culturais e políticas são também condições favoráveis, confirmando a hipótese da importância do contexto histórico-social para o desempenho da gestão? O u ainda, será que as experiências bem sucedidas se referem todas às chamadas "administrações democráticas?" Existe correlação significativa entre natureza partidária e desempenho da gestão?

No âmbito da literatura, alguns estudos sobre o que determina o sucesso de um governo local sinalizam na direção de que fatores estruturais como o desempenho fiscal dos governos determinariam o tipo e a possibilidade maior ou menor de sucesso de um dado governo local. De fato, a relação entre a esfera federal e as subnacionais muito se alterou com a nova correlação de forças pós-Constituinte. A gestão municipal apresenta, hoje, um caráter difuso, gerador de uma fragmentação de poder, mas, onde os políticos locais têm espaço próprio para desempenhar suas capacidades como gestores. Paradoxalmente a maioria dos municípios do N ordeste brasileiro (por exemplo) permanece fortemente dependente dos governos federal e estadual, além de exibirem, em sua maior parte, um déficit orçamentário e uma incapacidade de investimento. A reduzida produtividade 
das bases tributárias próprias, em termos de geração de receitas - que vinha sendo historicamente compensada por transferências negociadas de recursos estaduais e federais no modelo anterior - atualmente configura um quadro de fragilidade financeira. Isto significa que os municípios dependem, quase que exclusivamente, das transferências básicas de tributos, garantidas pela Constituição, dispondo de uma margem muito pequena de recursos a serem alocados livremente. Por outro lado, o município é continuamente pressionado a assumir encargos tradicionalmente debitados ao governo federal como aqueles ligados à implementação das políticas sociais e também aqueles ligados à infra-estrutura urbana de suporte. Em outras palavras, nesta abordagem, conter gastos e equilibrar o orçamento é o que definiria o desempenho fiscal de um município e o que condicionaria sensivelmente 0 tipo de gestão.

O utros trabalhos apresentam fatores associados diretamente ao nível e natureza das demandas sociais, como sendo fundamentais à definição do tipo de gestão. Nesta dimensão, a análise dos atributos da população municipal parece uma variável importante a ser considerada no que se refere ao grau de vulnerabilidade, índices de pobreza e acesso às políticas e programas sociais.

O utros estudos ainda sugerem que as investigações prossigam na perspectiva de analisar as reais condições político-institucionais da implementação da gestão pública no âmbito dos municípios. Por exemplo, há quase uma unanimidade em torno da idéia de que a participação concreta dos segmentos populares no processo decisório é condição básica para efetivação da gestão e, desta maneira, os recursos seriam destinados mais eficientemente, e o controle da aplicação dos mesmos seria da forma mais ampla possível. A abertura de novos canais de comunicação entre a sociedade civil e o poder político local, é entendida, assim, como instrumento fundamental da gestão pública, evidenciando inusitados aspectos da dinâmica política da sociedade civil. 
Sociologias, Porto Alegre, ano 8, № 16, jul/dez 2006, p. 86-125

Diante da evidência de tantos atributos distintos que parecem importar para o tipo e o desempenho da gestão municipal, significa perguntar: existe uma correlação possível entre o desempenho da gestão e as características de um município? 0 pressuposto de origem é de que é possível se identificarem fatores estruturais ou político-institucionais atrelados aos municípios aos quais correspondem perfis de desempenho da gestão. O u seja, a pesquisa se propôsa identificar, a partir da análise de indicadores de várias naturezas, grupos específicos de municípios que se caracterizam por padrões diferenciados de gestão pública.

O universo observado foi composto por 75 municípios do Nordeste brasileiro, localizados em Pernambuco, Paraíba e Rio Grande do Norte, durante a gestão municipal de 1993 a 1996. Analiticamente, no segundo tópico, exploram-se os termos e os argumentos do debate que focaliza os fatores que se associam ao desempenho da gestão pública em municípios. No terceiro tópico, discutem-se a seleção e a construção de um índice de aprovação popular como indicador de desempenho da gestão municipal. Nos quarto e quinto segmentos, apresentam-se e discutem-se: um modelo de análise para o desempenho da gestão municipal; a seleção e a construção dos indicadores de fatores determinantes desse mesmo desempenho; as hipóteses testadas e os resultados obtidos. Por fim, algumas considerações finais são apresentadas, incorporando-se elementos à reflexão sobre os limites e as potencialidades da descentralização a partir da Constituição de 1988. Embora não esteja centrado na análise da natureza dos gastos públicos municipais, o estudo acrescenta, assim, subsídios também ao debate sobre o (re) direcionamento dos gastos públicos nos municípios, revelando tendências de êxito para aqueles governos que priorizam determinados tipos de gastos ou setores de programas sociais específicos. 
Fatores associados ao desempenho da gestão pública: diferentes abordagens

A discussão do conceito de desempenho da gestão pública inicia-se pela distinção de que elementos - num leque de opções colocadas pela literatura existente sobre o tema, pelas evidências da observação empírica e pela informação disponível - devem e podem ser investigados enquanto seus determinantes. Diversas concepções colocadas pela teoria e pelo debate são aqui discutidas, com a perspectiva de seguir esta orientação. ${ }^{2}$

Em primeiro lugar, há análises que conferem grande ênfase a fatores de natureza estrutural, relacionados a características das unidades onde se realiza a gestão. Dentre eles destacam-se: fatores de ordem econômicofiscal, relativos à condição dos municípios de assumirem os custos financeiros das funções sob sua responsabilidade, ou fatores relativos às características do território ou da população ali localizada, ou ainda, fatores de natureza organizacionais, relacionados à capacidade técnica, os quais seriam decisivos para a qualidade ou tipo do desempenho da gestão. De uma maneira geral, na hipótese de que atributos estruturais dos municípios sejam fatores determinantes, o desempenho da gestão pública dependeria diretamente de sua eficiência de gasto ou de sua capacidade técnico-administrativa ou ainda de características referentes à dimensão e perfil de sua população.

O ra, é corrente no Brasil este tipo de argumento. Muitos dos trabaIhos que examinam o desempenho ou a capacidade dos governos locais restringem-se à análise das receitas (transferidas ou próprias), ou priorizam as despesas e endividamento realizados no respectivo âmbito de governo. ${ }^{3}$

2 Embora não exista um paradigma unificado que enlace teorias sobre o Estado e a gestão pública em municípios, há, de fato, uma análise sobre o tema em várias disciplinas, incluindo planejamento, ciência política, geografia, economia, administração e sociologia, sob abordagens diferentes. A temática proposta não encontra referências extensivas na Sociologia Clássica, inserindo-se, contudo, em discussões atuais presentes na Sociologia U rbana.

3 Referências clássicas incluem os trabalhos de SERRA e AFO NSO (1991); AFO NSO e SENRA (1994), MÉDICI (1994), AFO NSO (1995); AFFO NSO (1995 e 1995a); ANDRADE (1996 e 1999), além de outros. Recentemente é digno de nota o esforço de construção do Índice de Responsabilidade Fiscal e Gestão Social, da Confederação Nacional dos M unicípios que, apesar de se dispor a analisar a gestão social, ainda prioriza os indicadores relativos à capacidade de gasto . 
Sociologias, Porto Alegre, ano 8, no 16, jul/dez 2006, p. 86-125

A importância dada à variável "capacidade de gasto dos governos" para 0 percurso da gestão pública, tal como apresentada nos trabalhos referidos, demonstra a prioridade, conferida pelos autores, aos fatores de ordem estrutural. Tentando investigar o poder explicativo de variáveis de desempenho fiscal sobre o desempenho da gestão, no presente estudo são realizados testes empíricos com indicadores de evolução das receitas e gastos nas gestões municipais. Não há, contudo, nesta opção, o pressuposto conceitual de prevalência de determinantes desta natureza no desempenho dos governos. A idéia é verificar, ao lado de outros fatores que serão discutidos a seguir, se existe associação entre o desempenho fiscal e o respectivo desempenho da gestão.

Por decorrência das concepções referidas acima, predomina a noção de que, nas regiões menos desenvolvidas do País, onde a receita per capita é reduzida, haveria tendencialmente um baixo desempenho dos governos. A capacidade de gasto público seria positivamente afetada pela variável "base econômica", na medida em que esta define o volume de riqueza a ser taxada e, portanto, a base fiscal do nível de governo em questão. $\mathrm{O}$ u seja, a capacidade de gasto público teria o poder de definir o desempenho da gestão. N este estudo foi examinada, então, conforme sugere a teoria, a hipótese da dinâmica econômica dos municípios ser uma variável independente, capaz de isoladamente afetar o desempenho da gestão.

Seguindo esta lógica de influência dos fatores estruturais sobre o desempenho dos governos, inúmeros trabalhos baseiam-se na idéia de que a variedade de situações municipais, no que diz respeito ao perfil populacional, explicaria a qualidade do desempenho da gestão. 0 u seja, nesta linha de argumentos, muitos autores consideram que fatores expressivos do nível de desenvolvimento sócioeconômico e da qualidade de vida da população são determinantes para qualificar o desempenho da gestão.

Entre esses fatores, o porte do município, definido em termos populacionais, tem sido bastante recorrente nas análises. Influenciados pe- 
los estudos demográficos, bastante disseminados nos anos 60 e 70, muitos trabalhos realizados no Brasil estabelecem uma classificação prévia entre municípios, a partir do seu tamanho, que, supostamente, seria determinante da variação observada noutros atributos municipais. São exemplos desta linha de interpretação, trabalhos sobre descentralização tributária que classificam os municípios por sua dimensão populacional. Embora se aceite-se tal associação como verdadeira para o caso do desempenho fiscal, ${ }^{4}$ será que seria válida para o exame do desempenho da gestão como um todo? Com esta preocupação, a investigação presente testou a hipótese de que 0 porte do município, medido pelo tamanho de sua população, seja uma variável independente capaz de, isoladamente, explicar a variação dos desempenhos das gestões.

Ainda dentro de uma concepção que privilegia fatores de ordem estrutural, alguns estudos ${ }^{5}$ defendem que a "habilidade técnico-administrativa" (no sentido de gerência) do corpo gestor seria decisiva para o desempenho satisfatório da gestão. N essas concepções, a variável "habilidade técnico-administrativa" representa um elemento efetivo de diferenciação no desempenho de uma gestão.

Embora se aceite a importância da idéia, o presente estudo não contemplou os fatores específicos da "habilidade político-administrativa" como variáveis. Assume-se que as condições que definem a habilidade políticoadministrativa, entre municípios de pequeno porte do Nordeste, são muito pouco diferenciadas.

O s trabalhos que conferem importância decisiva a variáveis do tipo estrutural, como as referidas até aqui, relegam ao segundo plano ou desconsideram a natureza das políticas que definem e expressam as ações

4 GO M ES \& M ACD O W ELL (1995) discutem extensivamente as dificuldades encontradas por municípios de pequeno porte, sobretudo do Nordeste, configurando um quadro de inviabilidade fiscal, que, segundo os autores, seria o argumento principal para desbancar a idéia e a prática recente de proliferação de novos municípios.

5 REZEN DE (1999) analisa a relação entre habilidade administrativa e qualidade da gestão, a partir dos casos de Recife e Curitiba. 
Sociologias, Porto Alegre, ano 8, ํㅡ 16, jul/dez 2006, p. 86-125

dos governos. Há abordagens, contudo, que focalizam com maior ênfase fatores do tipo institucional para explicar, por exemplo, processos de reforma do Estado e/ou de descentralização. N esta vertente de interpretação, a ação dos governos é estruturada pelas instituições políticas, quer a noção de instituições refira-se à natureza das organizações, quer vincule-se às regras do jogo, isto é, ao conjunto de procedimentos legais que geram incentivos ao comportamento dos atores. Em estudos como os de LIM O NGI (1994); M ELO, M arcus André (2002) ou FERN AN DES (2002), considera-se que as instituições políticas têm relevância fundamental no desempenho dos governos.A contribuição dessas análises, no âmbito deste estudo, refere-se à inclusão de fatores relacionad os aos atributos político-institucionais como intervenientes no resultado das ações públicas. De maneira análoga, pressupõe-se que o desempenho da gestão, sobretudo de um governo municipal, é também resultado da interferência de fatores políticos associados às instituições, no âmbito das quais tomam-se as decisões e implementam-se as ações.

Especificamente neste estudo foi analisado o grau de disposição do governo municipal em adotar e implementar as políticas sociais. Considerando o processo de descentralização no País, mediante o qual, a partir dos anos 90, o governo federal vem delegando a estados e municípios grande parte das funções de gestão das políticas sociais, ${ }^{6}$ este é um aspecto importante a ser considerado. Contudo, no presente estudo, defende-se que as relações intergovernamentais, que são decisivas para o desempenho da gestão, definem-se reciprocamente entre os níveis de governo envolvidos. Com esta perspectiva, permitiu-se questionar se o estágio de implementação

6 Alguns autores afirmam que a ação dos governos locais, em estruturas federativas, depende em grande parte da ação do governo federal. Isto é, este último pode, unilateralmente, induzir decisões e comportamentos nos primeiros, por meio de programas deliberadamente desenhados para tal (ARRETCHE, 1999). Com base nesta premissa, em estados federativos, estratégias de indução de um nível mais abrangente de governo sobre um outro menos abrangente poderiam ter impacto sobre a criação de políticas públicas neste último. Neste ponto do argumento, ARREche acrescenta que a decisão de aderir ou não a um programa, por parte do governo local, dependeria da estrutura de incentivos (estratégias de indução) que lhe for oferecida. 
de uma política pública definida por um nível superior de governo seria suficiente para a descentralização daquela política, ou seria a disposição do governo local em aderir ao programa, mesmo incorrendo em alguns riscos, também importante no processo de descentralização? 0 u seja, será que 0 argumento de ARRETCHE (1999), válido para uma análise dos estados, seria válido também para os municípios? Será que a variação no grau de descentralização das políticas sociais encontrado nos municípios teria poder explicativo sobre a diversidade de desempenhos da gestão?

Numa abordagem alternativa às que privilegiam os fatores estruturais ou institucionais, alguns trabalhos examinam resultados do governo sob a perspectiva de sua ação política.

Segundo tais concepções, o desempenho da gestão pública poderia ser explicado por fatores ligados à ação política, na perspectiva de mobilização social local. O u seja, a natureza das relações entre Estado e sociedade, mais especificamente a capacidade de pressão da sociedade civil organizada sobre os governos locais, poderia definir o esforço em desempenhar bem funções relativas à oferta de serviços sociais, tornando a gestão eficaz. Com base nesta abordagem, este estudo que pretende analisar o desempenho da gestão em governos municipais, incorpora termose categorias da Ciência Política, que procuram explicar o Estado em ação, introduzindo elementos para uma reflexão sobre gestão pública local. As condições institucionais desta dinâmica, no entanto, merecem ser cuidadosamente analisadas, por constituírem uma das vias de resposta às demandas específicas pela democratização das políticas públicas, que as transformações descentralizadoras têm demandado. Assiste-se a dois níveis de transformações: em primeiro lugar, na ampliação do controle social sobre decisões públicas através de mecanismos de participação que envolvem a população diretamente. Em segundo lugar, pelo fortalecimento dos mecanismos de controle de política setorial, mediante a criação de instâncias de delibera- 
Sociologias, Porto Alegre, ano 8, ํㅡ 16, jul/dez 2006, p. 86-125

ção e consulta que aglutinam representantes dos interesses diretamente envolvidos, como também de entidades da sociedade civil, provedores de serviços e clientelas. ${ }^{7}$

Ponderação importante remete à dificuldade metodológica de obtenção de indicadores expressivos do capital social, que tem sido uma preocupação entre os estudiosos do assunto. Há uma dificuldade operacional concreta de se encontrarem, selecionarem, construírem e levantarem indicadores factíveis de medição, referentes ao desenvolvimento do capital social numa dada comunidade. A experiência obtida demonstra, no momento, as dificuldades metodológicas que análises deste tipo enfrentam.

A despeito das ponderações apresentadas à inclusão de fatores da ação política, na explicação do desempenho das gestões, acredita-se que nem os fatores estruturais, nem os institucionais, independentemente, têm poder explicativo sobre o desempenho da gestão. A complexidade de articulação entre esses fatores revela indubitavelmente as relações existentes entre variáveis referentes ao grau de autonomia municipal (estruturais), do padrão de formulação de políticas (político-institucionais) e da cultura política (ação social), desafiando modelos estreitos de explicação de desempenho da gestão. Ainda que de modo pouco preciso, o presente estudo assume que a idéia de "capital social" merece ser investigada na sua potencialidade de explicar o desempenho da gestão pública.

Retomando, então, o propósito da discussão aqui apresentada, quais elementos - entre as opções colocadas pela literatura específica, por evidências da observação empírica e pela informação disponível - devem e podem ser considerados para uma análise do desempenho das gestões locais? Q ual o peso dos atributos estruturais das localidades e unidades de

7 Alguns estudos recentes no Brasil se têm dedicado ao tema da participação sociopolítica, com uma contribuição relevante. Destaquem-se BO SCHI (1999), ABERS (2000), BAIO CCHI (2001), AVRITZER e NAVARRO (2003), CO ELHO e NOBRE (2004), CÔ RTES (2005), WAM PLER (2005), SCH NEID ER e GO LD FRANK (2005), LUBAM BO e CO ELHO (2005) entre outros. 
governo, tais como o desempenho fiscal ou as características dos municípios e a qualidade de vida de sua população, para o desempenho da gestão? Em que medida fatores de tipo político-institucional como a filiação partidária ou a continuidade administrativa interferem no escopo da gestão? A maior ou menor presença de Conselhos nos municípios seria determinante da qualidade da gestão local? A articulação existente entre níveis de governo é definidora do desempenho da gestão de políticas sociais em setores específicos? Enfim, supondo que todos esses fatores tenham um papel a ser considerado, qual ou quais deles seriam decisivos na avaliação do desempenho da gestão?

\section{A aprovação popular como indicador de desempenho da gestão municipal}

O primeiro desafio metodológico encontrado neste estudo foi definir um indicador para representar o desempenho da gestão. 0 ptou-se por utilizar um Indicador de Aprovação Popular relativo ao desempenho de cada governo municipal. Para tanto, foram utilizadas "surveys" específicas, sobre a avaliação que a população fez dos prefeitos, realizadas nos municípios em 1996.

A adoção do indicador de aprovação popular como um parâmetro do desempenho dos governos municipais remete a uma discussão específica e, até certo ponto, controversa. A ação pela qual a população confere valores ou índices de aprovação ao desempenho de uma gestão, não está referenciada numa literatura específica, e a literatura mais aproximada é a que trata do comportamento do eleitorado. Desta maneira, procurou-se a contribuição de estudos reconhecidos ${ }^{8}$ que balizam o pressuposto adotado neste estudo em que a opinião popular está pautada na avaliação racional que $o$ indivíduo faz do desempenho do governo.

8 FIO RINA, 1981; CARREIRÃO, 1999, VEIGA e MAGALH ÃES, 1999 entre outros. 
Sociologias, Porto Alegre, ano 8, ํㅡ 16, jul/dez 2006, p. 86-125

Assim, mesmo diante de algumas ressalvas importantes à capacidade da teoria da escolha racional na explicação do comportamento do eleitorado ou na predição dos resultados de uma eleição, mas à luz das opiniões predominantes na literatura, assume-se que os eleitores fazem uma escoIha racional no momento do voto e o fazem, baseados numa avaliação também racional, a respeito do desempenho do governo. Tal pressuposição baseia-se nos argumentos do "voto retrospectivo", cujas vertentes distintas de análise foram tratadas cuidadosamente por CARREIRÃO (1999):

I) a avaliação que o eleitor faz do desempenho da gestão;

II) o governo influencia seu voto. É a tese do "voto retrospectivo": eleitores que avaliam positivamente o governo em exercício tendem a votar no candidato do governo, enquanto eleitores que avaliam negativamente o governo tendem a votar na oposição;

III) a avaliação que o eleitor faz sobre o estado da economia influencia fortemente a avaliação que os eleitores fazem do governo e, portanto, sua decisão de voto. É a tese do "voto econômico": se a economia vai bem, o eleitor tende a votar no candidato do governo, e se ela vai mal, ele tende a votar na oposição, especialmente se o estado da economia puder ser claramente associado a certas ações do governo. Trata-se de uma versão particular do "voto retrospectivo".9

Embora este estudo sobre desempenho das gestões não trate especificamente 0 voto retrospectivo como os trabalhos referidos, acredita-se que a tendência (aliás, hegemônica dentro da Ciência Política) de entender 0 voto como expressão de uma avaliação prévia que o eleitor faz do governo, pode ser estendida para o entendimento da opinião pública. Se há uma tendência de que a votação seja influenciada pelo desempenho econômico na esfera nacional como aponta Carreirão, acredita-se, e, aliás, apresenta-

9 Como salienta Carreirão, há uma forte polêmica sustentada por autores como KrAmER (1971), Tufte (1975), LEwIs-BecK (1988), Paldam (1991), Remmer (1991), Powell \& Whitten (1993), Echegaray (1996), Cheibub \& Przeworski (1997), dentre outros. 
se como pressuposto neste trabalho, que a avaliação do desempenho do governo local é orientada pelos efeitos das ações desenvolvidas por aquele governo. O u seja, se as conclusões apresentadas pelo autor são válidas para o voto para o qual se inclui, implicitamente, a avaliação prévia do governo, tanto maior será a validade no caso de uma survey, em contexto não-eleitoral no qual se induz a tal avaliação.

0 objetivo no presente estudo não é o de aprofundar a investigação desta temática em relação ao eleitorado local nos municípios nordestinos, mas chamar a atenção, seguindo uma linha correlata à discussão anterior, para o fato de que o cidadão faz uma avaliação racional do seu governo quando é chamado a se pronunciar. O u seja, se parte significativa do eleitorado parece votar de acordo com sua avaliação sobre a gestão, quer-se saber que fatores são considerad os nessa avaliação (racionalidade) do cidadão para, então, apresentá-los como determinantes centrais do desempenho de governos locais.

U ma resistência possível à idéia de se aceitar a avaliação do eleitor como indicador de desempenho no poder da mídia de influenciar a opinião das pessoas. No trabalho de VEIGA e M AGALHÃES (1999), a preocupação foi, justamente, a de desvendar a maneira pela qual se forma a opinião do eleitor, investigando a influência da mídia. A noção de ideologia usada pelos autores foi bem específica. Foi conceituada como conjuntos de noções que possibilitam processos cognitivos e operatórios organizadores das perspectivas de decisão para os agentes, sempre em relação a um campo específico, no caso, as eleições presidenciais de 1998. Eles defendem que as ideologias marcam, para os agentes, posições e leituras específicas da realidade. Assim, a leitura ideológica seria sempre parcial, e, freqüentemente, tal parcialidade seria intencional. 0 s autores recusam a idéia de falsa-consciência, da maneira consagrada pela tradição marxista, e atribuem a essa tradição a noção de um caráter utilitário da ideologia, segundo a qual as 
teses que apostam no poder decisivo da mídia na formação da opinião do eleitorado se sustentam. Para o indicador de aprovação popular utilizado neste estudo, esta questão tem importância menor, uma vez que uma survey realizada fora do período de campanha eleitoral é menos contaminada pela propaganda.

Em síntese, esta exposição conceitual foi feita com a intenção de apresentar alguns pressupostos adotados neste estudo que elegeu a aprovação popular como indicador do desempenho da gestão. De antemão quer-se recusar o argumento de que o cidadão, o indivíduo que aprovaria ou deixaria de aprovar a gestão, seja movido por uma "falsa consciência". Assume-se que existe uma racionalidade individual embutida no índice de aprovação.

0 argumento da racionalidade do voto é adotado neste estudo, incorporando-se também pressupostos do individualismo metodológico ${ }^{10}$ para a compreensão dos atores sociais na gestão pública. Adota-se a concepção de ator social, utilizada por BOUDO N (1986), na qual a racionalidade só seria limitada em função de uma ausência de informação e de uma situação de incerteza. Toda ação é, em alguma medida e de algum ponto de vista, racional, posto que é mais ou menos consciente e mais ou menos transparente para 0 ator e observador. ${ }^{11}$ Entende-se que os indivíduos (atores sociais) encontram-se inseridos em um contexto que determina o campo das possibilidades e das restrições de ação (ainda que tal contexto não determine as escolhas). Mesmo que prevaleça a idéia de que a racionalidade seja limitada em função da posição que ocupa na estrutura social (ou na divisão de papéis) e da informação incompleta de que dispõe sobre a situação em que está inserido, o eleitor é um ator social, independentemente

10 Tais pressupostos conformam hoje uma das principais orientações da Sociologia cujo desafio é o de fornecer microfundamentos para os fenômenos sociaise, especificamente, basear as teorias nas ações dos indivíduos, concebidas como orientadas para a realização de objetivos racionais. (Przeworski, 1988).

11 Por este enunciado, a noção de racionalidade de Boudon parece bastante abrangente, distinguindo-se da concepção de Weber que se associava à noção de finalidade e, mesmo, da idéia de racionalidade de algumas correntes da chamada teoria da escolha racional (ELSTER, 1986), que se referiria tão somente à escolha do elemento/posição mais "valorado" dentro do conjunto plausível de alternativas. 
dos limites de sua racionalidade, e está inserido na gestão local, e, em tese, são importantes para o governo suas expectativas e apreciações. Com esta perspectiva, foi escolhida a aprovação popular como variável dependente e indicadora do desempenho da gestão municipal.

A metodologia adotada nas três surveys específicas realizadas em 1996 nos municípios, sobre a avaliação dos prefeitos, ${ }^{12}$ considerou um levantamento estatístico por amostragem estratificada, com cotas de sexo e idade, sendo a seleção dos entrevistados aleatória, com base rigorosamente domiciliar, o que garante uma margem de erro máxima, nos resultados de \pm 5 . $25 \%$, com um grau de confiança de $95 \%$. Esta equivalência de metodologia presente nas três pesquisas, permitiu uma comparação dos dados para municípios de estados distintos. A amostra foi estratificada com base nos dados censitários disponíveis para 1996, conforme divulgado pelo Instituto Brasileiro de Geografia e Estatística (IBGE). A coleta dos dados foi feita através de questionários, e a transcrição dos dados pesquisados foi tabulada e processada eletronicamente. As opiniões sobre o desempenho da gestão foram expressas em cinco categorias - ótima, boa, regular, ruim e péssima e calculadas em termos percentuais, sobre o total dos entrevistados. Com relação aos dados necessários à construção do Indicador de Aprovação Popular - $I_{A P}-$ foram agregadas as categorias BOA e Ó TIMA, obtendo-se a seguinte distribuição entre os municípios.

A partir da distribuição encontrada, os municípios foram agrupados nas seguintes categorias: I) índice de aprovação popular igual ou superior a $51 \%$, com $44 \%$ dos casos; II) índice de aprovação popular entre $20 \%$ e $50 \%$, representando $38 \%$ do universo dos municípios e III) índice de aprovação popular até $20 \%$, incluindo $20 \%$ do total de casos.

As variáveis independentes adotadas e o modelo de análise proposto para este mesmo desempenho estão descritos a seguir.

12 As "surveys" utilizadas foram fornecidas por três institutos de pesquisa de opinião: ARCO N SU LT (em Pernambuco); CO NSU LTPESQ UISA (no Rio Grande do Norte); Pesquisa \& Analise - P \& A (na Bahia). 
Sociologias, Porto Alegre, ano 8, № 16, jul/dez 2006, p. 86-125

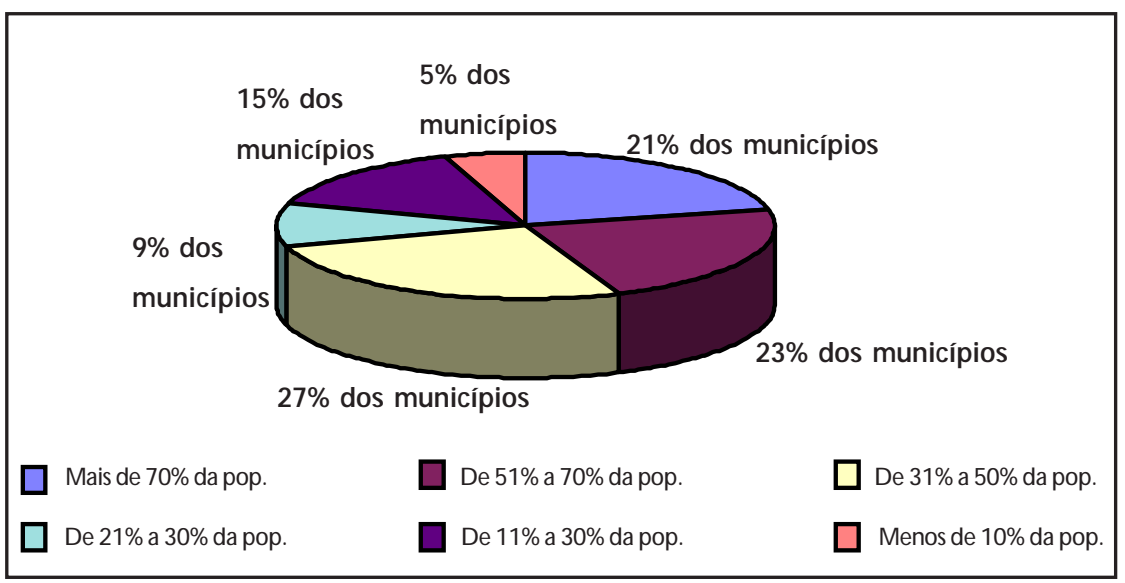

Gráfico 1- Distribuição do indicador de aprovação popular

\section{O Modelo analítico adotado: variáveis e teste de hipóteses}

Identificados distintos níveis de desempenho da gestão (associados aos diferentes níveis de aprovação popular), passou-se à reflexão sobre as possíveis razões pelas quais as gestões alcançaram seu nível de desempenho específico, dentro de um conjunto de municípios, num mesmo período. Buscar e investigar determinantes da gestão pública num contexto real é uma tarefa difícil, mas que, salvaguardando as limitações, foi experimentada neste estudo. O u seja, identificada a variação nos desempenhos das gestões, tratou-se de testar a capacidade de variáveis independentes para explicá-la. Neste momento, portanto, foi necessário traduzir cada variável em indicadores empiricamente observáveis e passíveis de comparação entre os municípios. 0 estudo considerou, assim, um amplo conjunto de variáveis a partir de cinco eixos analíticos:

I- Desempenho Fiscal, no qual se retratou o desempenho fiscal dos municípios selecionados, no período 92-96, a partir da evolução de 
algunsindicadores básicos: 0 grau de dependência das transferências governamentais (relação percentual entre as transferências correntes e as receitas totais apropriadas pelo município); o grau de comprometimento da receita (relação percentual entre a receita e as despesas com pessoal, incluindo encargose receitas totais) e a capacidade de arrecadação (receita total e tributária per capita). Em cada caso, a evolução dos indicadores no período da gestão foi considerada em trêsníveis: redução; manutenção e aumento (para a evolução do grau de dependência das transferências governamentais); redução; manutenção e aumento (para a evolução do grau de comprometimento da receita) e manutenção, alteração marginal e alteração pequena (para a evolução da capacidade de arrecadação).

II- Atributos Sociais da População, para o qual selecionaram-se indicadores de características e qualidade de vida da população habitante no município: IDHM , grau de desigualdade (Índice $L$ de Theil), percentual de pobres; taxa de mortalidade infantil, dimensão da receita municipal per capita, porte populacional do município e grau de urbanização. A evolução desses indicadores, uma a uma, foi definida em três níveis, conforme a distribuição apresentada por cada variável escolhida.

III- Participação Popular, no qual se buscou apreender a tradição associativa da população. Neste caso, o indicador sugerido pela literatura e pelo senso comum seria a atuação de associações ou organizações não-governamentais de interesse coletivo ou comunitário. Para além das ponderações conceituais e metodológicas já apresentadas, a ausência expressiva das O N Gs em localidades fora das grandes áreas urbanas no Nordeste, constituiu fator decisivo para a não inclusão desse indicador. A opção, pela recorrência e importância no contexto recente da descentralização no País, recaiu sobre a presença dos conselhos municipais, nos vários setores, identificada em três 
Sociologias, Porto Alegre, ano 8, № 16, jul/dez 2006, p. 86-125

níveis: I) até um conselho presente; II) até três conselhos presentes e III) mais de quatro conselhos presentes. A reduzida presença de O N Gs em municípios longínquos cria obstáculos à capacidade, em número ou em competência, de essas organizações chegarem a influenciar no desempenho da gestão municipal. Neste sentido, a presença de conselhos aparece como um indicador mais significativo quando se refere à possibilidade de a população influir na gestão das políticas municipais.

Salvaguardando os limites contid os nesta representação e no seu significado de participação, a mesma idéia pode ser indicada pela maior ou menor presença de um conjunto de entidades, entre as quais os conselhos setoriais, nas quais a sociedade esteja representada. $\mathrm{O}$ u seja, não se quer atribuir maior valor de participação aos municípios nos quais compareçam um maior número de entidades, mas há que se reconhecer a existência de atributos distintos entre gestões que tenham conseguido instituir números diferentes de conselhos. A rigor, as diferenciações no quadro da presença dos conselhos existentes entre os municípios, serão examinadas mais como atributos de ação política, na possibilidade de explicar a variação no desempenho das ações políticas setoriais e, conseqüentemente, no desempenho da gestão.

IV- Evolução do Atendimento em Serviços Públicos, mediante 0 qual se diagnostica a evolução do atendimento público municipal nos setores de educação e saúde, setores básicos em que a responsabilidade municipal está claramente definida. Foram selecionados dois indicad ores fundamentais para os setores considerados: $\mathrm{Na}$ área de educação, a evolução do nível de atendimento em pré-escolas municipais, considerando o contingente de crianças entre 3 e 6 anos. $\mathrm{Na}$ área da saúde, a evolução do nível de atendimento em internações hospitalares pediátricas no município. Supõe-se que a evolução do atendimento público setorial permite indicar até que ponto as ações 
da Administração nos setores avaliados contribuíram para a melhoria da qualidade de vida no município, sinalizando a eficácia das políticas públicas municipais. Por outro lado, a avaliação das atividades desenvolvidas pela Administração, considerando que o volume de recursos disponíveis quase não se altera, revela o grau de eficiência da gestão.

V- Descentralização de Programas Sociais, onde se investiga 0 grau de participação dos municípios em programas sociais descentralizados, quer seja por uma adesão deliberada ou mediante uma avaliação de custo $x$ benefício, sugerida pelos mecanismos de indução presentes na municipalização dos serviços, como indicador do comprometimento do poder público instituído. Foi analisada a evolução da taxa de municipalização do ensino fundamental em três níveis - aumento, manutenção e redução e as condições de adesão ao PACS/PSF, observados em três estágios - ausente, PACS presente e PACS e PSF presentes. Acrescentaram-se, como variáveis importantes neste eixo, a condição de continuidade político-administrativa, em relação à gestão anterior e o partido político da gestão. 0 grau de descentralização desses programas sociais foi calculado para cada município, em relação ao nível médio de sua respectiva unidade federativa.

Testar o poder explicativo da variável filiação partidária sobre o desempenho das gestões não foi uma decisão fortuita. Por um lado, pressupõe-se que o Partido seja uma instituição que define princípios, prioridades programáticas, condutas e normas aos seus filiados. Por outro, tem sido recorrente, na literatura e no senso comum, a idéia de que ideologias distintas definem padrões distintos de gestão, com desempenhos presumidamente diferentes. Muito embora a distinção de ideologias não seja 0 critério definidor da distinção e da diversidade partidária no País, foi analisado o nível de associação existente entre o Partido, como ente institucional, e o desempenho obtido na gestão. 
Sociologias, Porto Alegre, ano 8, № 16, jul/dez 2006, p. 86-125

Não são raras as situações em que a descontinuidade entre governos tem sido apresentada como limitante ao desempenho das gestões locais. O s argumentos que concorrem para esta tese são vários: a desmobilização do aparato governamental; a substituição dos cargos ou dos ocupantes dos cargos; 0 abandono de programas em desenvolvimento; o tempo necessário à elaboração de planos de ação, entre outros. Com base nestes argumentos, neste trabalho é investigado empiricamente se é possível estabelecer uma associação entre a continuidade político-administrativa e o desempenho da gestão.

Construíram-se então duas hipóteses na perspectiva de avaliar o peso dosfatores selecionados para os cinco eixos analíticos, no desempenho das gestões municipais:

- HIPÓ TESE 1: existem fatores capazes de, isoladamente, interferirem no desempenho da gestão, para todo tipo de município.

- HIPÓ TESE 2: existem fatores capazes de, em conjunto, interferirem no desempenho da gestão de um dado perfil de municípios. Restando, por acréscimo, desvendar os fatores explicativos e os perfis de municípios.

\section{Interpretação dos dados e dos resultados obtidos}

Para a análise proposta, construiu-se um banco de dados composto das seguintes variáveis:

Para a interpretação dos dados levantados, o modelo analítico adotado seguiu os procedimentos estatísticos básicos de verificação da simetria (teste de skewness) para cada uma das variáveis. Para a variável dependente foi obtido resultado satisfatório, $s=0,18$, o que serviu de base para as duas hipóteses de trabalho.

Considerando a Hipótese 1, cada uma das variáveis independentes foi submetida à verificação de simetria (teste de skewness), depois do que, 
algumas delas foram transformadas em variáveis logarítmicas e outras duas, excluídas da matriz de análise, como é o caso do partido político da gestão e condições de adesão ao PACS/PSF. Foi verificada a matriz de correlação bivariada entre as variáveis independentes e o indicador de Aprovação Popular, conforme demonstrado no Q UADRO ESTATÍSTICO 1.

\begin{tabular}{|l|l|r|l|}
\hline \multicolumn{4}{|l|}{ Identificação das Variáveis } \\
\hline \multicolumn{4}{|l|}{} \\
\hline v1 & Poptot96 & v14 & Evol. Tributos per capita \\
\hline v2 & U rbaniz96 & v15 & ICV PNUD \\
\hline v3 & CrescPopurb & v16 & IDH PNUD \\
\hline v4 & CrescPoptotal & M ort PNUD \\
\hline v5 & EvoluU rbaniz & v18 & \% Pobres \\
\hline v6 & AtendSaúde & v19 & Desigualdade \\
\hline v7 & Aprovação Popular & v20 & Participação Popular \\
\hline v8 & RecMédia & v21 & Continuidade Partidária \\
\hline v9 & CompM éd & v22 & $\begin{array}{l}\text { Evol } \\
\text { GrauMunicipalEnsFund }\end{array}$ \\
\hline v10 & DepedM éd & v23 & AtendEduca \\
\hline v11 & Evol. Dependência Transf. & v24 & Taxa EducaçãoPN UD \\
\hline v12 & Evol. Comprometimento & v25 & Evolução Pré-escolar \\
\hline Receita & Evol. Receita per capita & v26 & $\begin{array}{l}\text { Graus } \\
\text { MunicipalEnsFund }\end{array}$ \\
\hline
\end{tabular}


Sociologias, Porto Alegre, ano 8, oㅡ 16, jul/dez 2006, p. 86-125

QUADRO ESTATÍSTICO 1

Correlações: variáveis x indicador aprovação popular

\begin{tabular}{|c|c|c|c|c|c|}
\hline & V1 & V2 & V3 & V4 & V5 \\
\hline V7 & $-0,0785$ & $-0,11$ & 0,1226 & $-0,06$ & 0,2909 \\
\hline & V6 & V8 & V9 & V10 & V11 \\
\hline V7 & $-0,005$ & $-0,0382$ & 0,1506 & 0,163 & 0,1113 \\
\hline & V12 & V13 & V14 & V15 & V16 \\
\hline V7 & $-0,0716$ & 0,0448 & 0,0582 & $-0,0766$ & $-0,106$ \\
\hline & V17 & V18 & V19 & V20 & V21 \\
\hline V7 & $-0,0562$ & 0,1013 & $-0,0684$ & 0,1417 & 0,1954 \\
\hline & V22 & V23 & V24 & V25 & V26 \\
\hline V7 & $-0,1029$ & $-0,1657$ & 0,146 & $-0,2019$ & 0,1029 \\
\hline
\end{tabular}

Como se pode atestar, nenhuma variável independente registrou um nível de correlação expressivo junto ao IAP, para o total de casos. 0 u seja, não foram identificadas variáveis cujos níveis de correlação indicassem sua capacidade de isoladamente interferir no desempenho da gestão. Isto não significa que os fatores e atributos específicos de um dado município não sejam variáveis capazes de interferir no desempenho da gestão municipal.

$\mathrm{Na}$ verdade, cada variável pode condicionar o perfil da gestão municipal, embora sua interferência nos resultados da gestão não pareça ser direta. Significa que isoladamente uma variável não explica a variação no desempenho da gestão nos municípios, para todos os casos examinados, podendo, contudo estar associada a outras que, em conjunto, podem ser significativas para um grupo ou grupos de municípios. É o que se buscou verificar com a Hipótese 2, a partir desse ponto. 
Sociologias, Porto Alegre, ano 8, № 16, jul/dez 2006, p. 86-125

Na análise da H ipótese 2, a idéia foi testar a existência de uma tipologia que superasse a questão: existem grupos distintos de municípios, no interior dos quais o desempenho da gestão apresente um comportamento semeIhante? E que atributos municipais seriam definidores desses grupos?

A opção metodológica foi investigar, a partir de entrevistas com 13 prefeitos, uma amostra aleatória, entre aqueles 32 , cujas gestões apresentavam indicadores de aprovação popular BO M ou Ó TIM O, quais características evidenciadas na gestão eram comuns. A intenção foi identificar a congruência ou diversidade dos padrões das gestões municipais bem sucedidas. A rigor, diferentes modelos de gestão não podem ser pensados apenas como alternativas boas em si, mas acredita-se que sinalizam para aspectosque possam ser reproduzidos como determinantes do bom desempenho.

Desta investida, definiram-se categorias que passaram a representar conjunto de fatores capazes de interferir no desempenho da gestão de um dado perfil de municípios:

- o da eficácia das políticas sociais- expressa pela evolução do atendimento em educação e saúde;

- 0 esforço fiscal - indicado pela variável de evolução do comprometimento da receita com gastos em pessoal;

- o perfil de compromisso social do prefeito - identificado pelas variáveis de adesão aos programas sociais descentralizados.

M ediante uma análise de "clusters", foi possível identificar grupos de casos relativamente homogêneos quanto ao desempenho da gestão, baseados em atributos selecionados dos municípios. 0 objetivo foi criar um agrupamento hierarquizado, onde são reduzidas as variâncias intragrupos e maximizadas as variâncias entre os grupos encontrados. Cada grupo foi composto por um número expressivo de casos, considerando o total da amostra, e definido por variáveis significativas com comportamentos diferentes para cada grupo. 
Sociologias, Porto Alegre, ano 8, № 16, jul/dez 2006, p. 86-125

Normalmente a análise de "clusters" tem sido utilizada quando a definição de grupos, baseada em variáveis indicadas pelos argumentos e pressupostos da teoria, não se mostra aceitável. 0 procedimento básico adotado aqui consistiu numa série de experimentações mediante as quais foram testados atributos selecionados, na sua capacidade de definir um número pequeno de grupos. A observação do comportamento de cada variável, dentre aquelas escolhidas para o conjunto dos casos, foi decisiva na escolha dos atributos definidores dos "clusters", bem como do próprio número de "clusters", no qual seria classificada a amostra.

Foram experimentadas três tipologias de municípios a partir dos indicadores selecionados, representantes das ações efetivas da gestão, conforme as categorias acima referidas. A matriz final cluster centersapresentada a seguir mostrou-se a mais significativa para representar uma tendência de agrupamento entre os municípios:

\begin{tabular}{|c|c|c|c|}
\hline CLUSTERS & $\begin{array}{c}\text { Evol. Comprom. } \\
\text { Receita }\end{array}$ & $\begin{array}{c}\text { Municipal } \\
\text { Ens. Fundamental }\end{array}$ & $\begin{array}{c}\text { Evol. } \\
\text { Atendim. Saúde }\end{array}$ \\
\hline 1 & -1.5127 & -0.4732 & -0.0237 \\
\hline 2 & 0.5940 & 0.7504 & -0.4673 \\
\hline 3 & 0.5807 & -0.5793 & 0.6515 \\
\hline
\end{tabular}

Variables Saved into Working File

Q CL-28 (Cluster Number) e Q CL - 29 (Distance)

\section{GRUPO 1}

Número de Casos - 21 (28\% do universo).

Características - reduziu ou manteve o nível de comprometimento da receita com despesas em pessoal; não alterou a taxa de municipalização do ensino fundamental e manteve estável a situação do atendimento em saúde. 


\section{GRUPO 2}

Número de Casos - 31 (41\% do universo).

Características - aumentou o comprometimento da receita com despesas em pessoal, não apresentou significativa evolução na taxa de municipalização do ensino fundamental, mas melhorou o atendimento em saúde (com redução das internações hospitalares pediátricas).

\section{GRUPO 3}

Número de Casos - 23 (31\% do universo).

Características - aumentou o comprometimento da receita com gastos em pessoal; piorou o atendimento em saúde (com aumento das internações hospitalares pediátricas), embora tenha evoluído a taxa de municipalização no ensino fundamental.

É importante ressaltar que o aumento do comprometimento da receita com gastos em pessoal, esteve vinculado, na quase totalidade dos casos, à evolução na oferta dos serviços públicos. O u seja, a evolução dos gastos em pessoal, nestes casos, parece significar um aumento de gastos sociais. Sobretudo se for considerado que o investimento social em pequenos municípios está representado praticamente pela contratação de pessoal e serviços especializados de médicos, enfermeiros, agentes de saúde, auxiliares ambulatoriais, professores e profissionais na área de educação, esta hipótese é bastante plausível.

Analisando em seguida os índices de aprovação popular para os grupos propostos, foi possível encontrar resultados significativos:

\begin{tabular}{|l|cc|cc|cc|cc|}
\hline \multirow{2}{*}{$\begin{array}{l}\text { Aprovação Popular } \\
\text { (Ó tima + Boa) }\end{array}$} & \multicolumn{7}{|c|}{ Tipologia dos Municípios } \\
\cline { 2 - 10 } & \multicolumn{2}{|c|}{ Grupo 1 } & \multicolumn{2}{|c|}{ Grupo 2 } & \multicolumn{2}{c|}{ Grupo 3 } & \multicolumn{2}{c|}{ Total } \\
\hline Mais de 51\% & 9 & $12,0 \%$ & 15 & $20.0 \%$ & 8 & $10.7 \%$ & 32 & $42.6 \%$ \\
\hline De 20\% a 50\% & 7 & $9.3 \%$ & 11 & $14.7 \%$ & 10 & $13.3 \%$ & 28 & $37.3 \%$ \\
\hline Até 20\% & 5 & $6.7 \%$ & 5 & $6.7 \%$ & 5 & $6.7 \%$ & 15 & $20.1 \%$ \\
\hline Total & 21 & $28.0 \%$ & 31 & $41.3 \%$ & 23 & $30.7 \%$ & 75 & $\begin{array}{c}100.0 \% \\
\%\end{array}$ \\
\hline
\end{tabular}


Sociologias, Porto Alegre, ano 8, № 16, jul/dez 2006, p. 86-125

Distribuição dos municípios segundo a tipologia sugerida pela análise de Cluster por níveis de aprovação popular

A maior concentração de municípios foi registrada no Grupo 2, com os melhores índices de aprovação. 0 Grupo 2 ainda aparece na segunda posição com os segundos melhores índices, seguido do Grupo $3 \mathrm{com}$ os terceiros melhores índicese, do Grupo 1 com piores índices de aprovação. Se a observação for feita, no interior dos grupos, registros semelhantes foram feitos: no Grupo 2, há uma maior concentração para os melhores índices; no Grupo 3, para os índices médios e no Grupo 1, apresentando uma concentração relativa maior nos piores índices.

O u seja, é nítida a tendência de associação entre os melhoresíndices e os municípios que aumentaram o comprometimento de sua receita com pessoal e, embora não tenha apresentado evolução significativa na municipalização do ensino fundamental, melhoraram o atendimento em saúde (com redução das internações hospitalares pediátricas). Por outro lado, aqueles municípios onde houve um aumento do comprometimento da receita com gastos em pessoal, e, embora tenham piorado o atendimento em saúde (com aumento das internações hospitalares pediátricas), evoluíram na municipalização no ensino fundamental, exibindo assim índices médios de aprovação. E por fim, os municípios que reduziram ou mantiveram o comprometimento da receita com gastos em pessoal e não investiram em serviços públicos - não alteraram a municipalização do ensino fundamental e mantiveram estável a situação do atendimento em saúde tenderam a apresentar baixosíndices de aprovação.

Estes resultados vêm reforçar a hipótese de que o desempenho da gestão municipal, indicado pelo grau de aprovação popular, está associado prioritariamente aos fatores vinculados à natureza da ação política empreendida na gestão. Dentre esses fatores, aqueles associados à disposição do gestor e à opção que é dada ao enfrentamento das políticas sociais são 
fatores decisivos. Vale reafirmar que, de modo recorrente, os prefeitos das gestões bem-sucedidas, sem estar previamente informados sobre o fato, referiram-se à melhoria da saúde e da educação, como tendo sido uma prioridade do seu governo. Independentemente da forma adotada para tal enfrentamento, se mediante programas descentralizados, se mediante ações de iniciativa própria, de natureza muitas vezes específica (como a oferta de transporte escolar e de ambulâncias; a oferta de refeições a gestantes e crianças menores de um ano, etc.), a atenção aos serviços básicos foi uma constante nos discursos, confirmados pela análise dos dados da pesquisa.

U ma especificidade, contudo, que em meio a tais resultados, merece ser evidenciada é a nítida tendência de associação entre os melhores índices e os municípios que evoluíram o atendimento em saúde (com redução das internações hospitalares pediátricas), embora não tenham apresentado evolução significativa na municipalização do ensino fundamental. Esta vantagem dada às ações de saúde como determinante do desempenho das gestões expresso na aprovação popular, é uma indicação da urgência com que deve ser encarado o setor em face das carências e demandas existentes.

\section{Considerações finais}

A primeira conclusão, de ordem geral, resultante da pesquisa sugere que, longe de se querer associar um único fator, ou fatores de uma mesma natureza, ao desempenho da gestão dos municípios, a confirmação é de que existe um conjunto de fatores capazes de interferir nesse desempenho. Ao mesmo tempo, resultados do estudo demonstram que outros fatores, freqüentemente associados ao desempenho da gestão, parecem não ter o poder explicativo que lhes é atribuído. As conclusões obtidas e a discussão sugerida a partir deste ponto, conduzem à defesa do seguinte argumento: não é possível estudar o desempenho da gestão a partir da 
Sociologias, Porto Alegre, ano 8, № 16, jul/dez 2006, p. 86-125

singularidade de um tipo de fator: de natureza estrutural, político-institucional ou mesmo da ação política, mas deve prevalecer a idéia de uma associação multivariada.

As hipóteses apresentadas e discutidas no estudo orientaram-se pela preocupação em distinguir os fatores que teriam capacidade explicativa sobre o desempenho da gestão municipal. Diversas concepções colocadas pela teoria foram discutidas. Em primeiro lugar, foram postos em evidência estudos que costumam conferir ênfase a atributos de natureza estrutural dos municípios, como fatores de ordem econômico-fiscal ou fatores relativos às características do território ou da população ali localizada.

Dentro desta perspectiva, os resultados encontrados sugerem que 0 exame do desempenho dos governos locais não seja restrito à análise das receitas (transferidas ou próprias), despesas e endividamento, realizados no respectivo âmbito de governo. $\mathrm{Na}$ investigação sobre o poder explicativo de indicadores do desempenho fiscal sobre o desempenho da gestão, não se verificou nenhuma ascendência destes determinantes sobre outros indicadores. O u seja, recusa-se a idéia de que a qualidade das gestões seja prioritariamente afetada pelo desempenho fiscal, muito embora a viabilidade fiscal seja uma condição necessária à efetivação dos governos.

A evidência mais importante no exame dos indicadores do desempenho fiscal foi a de que um aumento no comprometimento da receita municipal com gastos em pessoal não significa necessariamente ineficiência da gestão ou "inchaço" da máquina pública. Algumas polêmicas parecem movimentar o debate em torno desta questão: tal aumento poderia ser um indicador da adequação do quadro do município às novas atividades realizadas pelos governos locais, ou prevalece ainda a possibilidade de que esse gasto continue alimentando relações de troca política que têm por base 0 emprego público?

A partir dos resultados deste estudo, registrou-se uma associação nítida entre o aumento do comprometimento da receita (com gastos em pessoal) 
e a adesão a um programa setorial ou a evolução da oferta de serviços públicos. O u seja, a despeito da necessidade de estudos que demonstrem concretamente como os municípios têm aplicado a parcela fiscal que foi adicionada à sua receita a partir de 1988, à luz desses resultados, é possível afirmar que 0 aumento do gasto público nos municípios, para um número significativo de casos, está associado a gastos na oferta de mais empregos, vinculados aos serviços municipais de saúde e educação, em decorrência da descentralização das políticas sociais. 0 bviamente que tal constatação não descarta a tese de "inchaço"da máquina pública para alguns casos e mesmo, não contraria a idéia de um superdimensionamento dos empregos (baseado na subutilização dos recursos humanos), contudo sugere que as análises não sejam precipitadas em apontar o empreguismo político como causa principal da evolução dos gastos com pessoal.

As evidências apontadas pelo presente estudo, considerando, obviamente, seus limites, indicam que a idéia de que os governos municipais comprometem desordenadamente sua receita com pessoal à margem de uma política de prioridades não pode ser tomada como padrão. Entre os 75 casos estudados, esta situação não foi a predominante; e, ao contrário, os aumentos nos gastos de pessoal na sua totalidade aparecem associados a uma evolução no atendimento de educação ou de saúde, ou nos dois setores simultaneamente. A experimentação analítica apontou, inclusive, para a possibilidade de se criar uma tipologia para os padrões de gestão, baseada na natureza e dimensão do gasto público, para os quais podem ser atribuídas diferentes avaliações de desempenho pela própria população. A compreensão e apuração deste critério poderão subsidiar não só a teoria sobre o tema, mas a prática e as estratégias utilizadas pelas instituições envolvidas, na perspectiva de melhor definir e prever as repercussões da descentralização fiscal e das políticas públicas.

Ainda como resultado do teste da influência dos fatores estruturais, refuta-se a noção de que, nas localidades menos desenvolvidas onde a 
Sociologias, Porto Alegre, ano 8, no 16, jul/dez 2006, p. 86-125

receita per capita é reduzida, haja uma tendência a um baixo desempenho dos governos. Embora a receita média seja um indicador positivamente afetado pela "dinâmica econômica" do município, a partir dos resultados deste estudo, conclui-se que o volume de receita dos municípios não é uma variável independente, capaz de, isoladamente, afetar o desempenho da gestão.

Para além dos resultados encontrados no exame das variáveis de cunho estrutural, o estudo analisou fatores político-institucionais na sua capacidade de explicar o desempenho da gestão, encontrando resultados importantes. Foram considerados centralmente alguns fatores do tipo políticoinstitucional, tais como a filiação partidária do governo; a continuidade político-administrativa; a disposição do governo local em assumir políticas sociais; a participação popular, entre outros. A hipótese de que existe um poder explicativo da variável filiação partidária sobre o desempenho das gestões não foi confirmada por este estudo. N enhuma associação significativa entre o partido como ente institucional e o desempenho obtido na gestão foi encontrada. Talvez pela própria inorganicidade, característica dos partidos nacionais, que só no Congresso adquirem unidade, o partido não possa ser concebido como uma instituição capaz de definir padrões diferenciados de gestão local.

Investigando a hipótese de que a continuidade ou descontinuidade entre governos seria um fator influente no desempenho das gestões locais, foi analisada esta variável, não sendo possível, contudo, estabelecer uma associação significativa entre as variáveis. É provável que mudanças casuísticas de legenda partidária, com nítido efeito eleitoreiro, como também as alianças e coligações entre partidos sejam empecilhos à utilização da simples comparação de legendas partidárias como indicadores de uma continuidade político-administrativa.

Como fator vinculado à ação política empreendida na gestão, foi examinada a disposição do governo local para enfrentar as políticas sociais. As 
evidências reforçam a tese de que a ação dos governos locais, em estruturas federativas, depende em grande parte da ação do nível superior de governo, mas apontam para a importância decisiva da disposição do governo local para o enfrentamento das políticas sociais. 0 u seja, o que os resultados sugerem é a existência de uma firme determinação, por parte dos prefeitos, de priorizar as políticas sociais, quer tratem de uma ação descentralizadora, com a indução do governo federal e estadual, quer se refiram a iniciativas próprias.

Q uanto à participação política não foi possível encontrar resultados significativos. Algumas ponderações são aqui retomadas: a primeira referese às evidências, já apontadas por vários autores, ${ }^{13}$ de causalidade recíproca entre a consolidação da sociedade civil e a melhoria no desempenho do governo, assinalando que a atuação do governo, mediante mecanismos institucionais variados, tem sido decisiva para a participação popular na esfera pública; outra ressalva refere-se à dificuldade de se distinguirem empiricamente entidades de papel (como é o caso dos registros de implantação de conselhos setoriais) daquelas orgânicas de fato (para cuja evidência, seria necessário uma análise sobre a atuação de cada Conselho registrado); e por fim, quer-se enfatizar a emergência da análise de redes sociais para 0 estudo das relações entre 0 Estado e a sociedade mais ampla. ${ }^{14}$

0 presente estudo comparado sobre desempenhos de governos locais no N ordeste brasileiro, propõe uma tipologia para os municípios, com base na semelhança intragrupos e na diversidade entre grupos: Foram identificados três grupos de municípios: I) os que apresentaram os melhores índices de aprovação são os municípios que aumentaram o comprometimento de sua receita com pessoal e, embora não tenham apresentado evolução significativa na municipalização do ensino fundamental, melhora- 
Sociologias, Porto Alegre, ano 8, № 16, jul/dez 2006, p. 86-125

ram 0 atendimento em saúde (com redução das internações hospitalares pediátricas); II) aqueles municípios que exibiram índices médios de aprovação, nos quais houve um aumento do comprometimento da receita com gastos em pessoal, e, embora tenham piorado o atendimento em saúde (com aumento das internações hospitalares pediátricas), evoluíram na municipalização no ensino fundamental, e III) os municípios que apresentaram baixos índices de aprovação, os que reduziram ou mantiveram 0 comprometimento e não investiram em serviços públicos - não alteraram a municipalização do ensino fundamental e mantiveram estável a situação do atendimento em saúde.

Estes resultados vêm reforçar a hipótese de que o desempenho da gestão municipal, indicado pelo grau de aprovação popular, está associado prioritariamente aos fatores vinculados à natureza da ação política empreendida na gestão, condicionados obviamente por algumas características de viabilidade fiscal no município. D entre esses fatores, aqueles associados à disposição do gestor e à opção que é dada ao enfrentamento das políticas sociais são fatores decisivos. Independentemente da forma adotada para tal enfrentamento, mediante programas descentralizados ou recorrendo a ações de iniciativa própria, os governos locais que privilegiaram a atenção aos serviços básicos e obtiveram resultados evidentes estavam entre as gestões bem sucedidas. M erece ser evidenciada também a nítida tendência de associação entre os melhores índices e os municípios que evoluíram no atendimento em saúde, com vantagem sobre 0 atendimento em educação.

O utra conclusão sugerida pela pesquisa remete à proposta metodológica de eleger a aprovação popular como indicador do desempenho da gestão pública. A seleção da aprovação popular pressupôs, obviamente, que tal indicador refletisse diferenças expressivas entre as gestões, e congruentes quanto ao desempenho da gestão. 0 questionamento possível recaía sobre se tais diferenças seriam de fato perceptíveis aos protago- 
nistas da avaliação. M elhor explicando, se as diferenças medidas pelos indicadores "objetivos" selecionados seriam percebidas pela população a ponto de refletir no nível de aprovação. O u seriam os critérios de avaliação tão idiossincrásicos e impregnados de relativismo cultural ou identidade local que tornariam o julgamento da população incompatível com qualquer avaliação sugerida pela teoria? Em outras palavras, seria a aprovação popular uma manifestação "racional"?

A questão foi bastante discutida no tópico 3 deste artigo, argumentando-se em favor da aceitação da idéia de que a aprovação popular seria, de fato, uma manifestação racional. Contudo a dúvida permanecia sobre se as diferentes necessidades, expectativas e níveis de satisfação dos habitantes de distintas localidades, originariam opiniões comparáveis, cujas associações com os determinantes fossem factíveis (não espúrias). As evidências do estudo demonstraram que os cidadãos têm uma idéia comum sobre 0 que é qualidade e o que é defeito da gestão e revelaram essa idéia ao associar bons níveis de desempenho com evoluções positivas de atendimento ou ações públicas. Esta constatação é importante, não só para validar a utilização do indicador de aprovação popular como expressão do desempenho da gestão, mas também para enfatizar a relevância da opinião da população como fator decisivo na avaliação de desempenho dos governos. Embora a ação dos governos locais, a partir da descentralização, venha recebendo considerável reforço de diversos estudos, são desconhecidas análises que se preocupam em qualificar e comparar desempenhos, associando-osà satisfação popular.

Por fim, acrescentaram-se subsídios ao debate sobre a descentralização recente das políticas sociais no País, que tem sido um tema privilegiado no debate atual. Para uns, o impacto da descentralização se traduziria de fato, em transformações no conteúdo e na natureza dos gastos do governo, havendo uma orientação para o gasto em programas sociais, enquanto para 
Sociologias, Porto Alegre, ano 8, № 16, jul/dez 2006, p. 86-125

outros, haveria um estímulo a práticas clientelísticas e de favorecimento. A tendência predominante para a análise dos impactos da descentralização tem-se apoiado no pressuposto de que a Constituição de 1988 teria produzido um conjunto de problemas de competências e gestão, aliando-se a ineficiências variadas. Entre essas ineficiências, para restringir-se ao argumento em discussão, seria a preferência alocativa dos governos municipais, voltada à distribuição do emprego público. A julgar pelos resultados encontrados, contudo, a primeira hipótese é mais provável de se confirmar, ou mesmo uma combinação das duas alternativas, com a ampliação dos serviços sociais simultaneamente à distribuição de empregos públicos.

Por fim, este estudo salienta alguns equívocos presentes em trabalhos que focalizam os efeitos da descentralização, pautando suas análises, muitas vezes, sem referências empíricas, na inviabilidade e inoperância dos governos municipais. Reforçar a viabilidade de governos municipais, com base na evidência de bons desempenhos, é importante, na medida em que os municípios cumprem um papel central em assegurar a governabilidade como peças fundamentais na estrutura federativa.

\section{Referências}

ABERS, R.. Inventing local democracy: grassroots politics in Brazil. Boulder: Lynne Rienner Publishers.2000.

AFFO NSO, R. de B. "A crise da federação no Brasil". Texto apresentado ao Seminário Internacional, "Impasses e Perspectivas do Federalismo no Brasil", IESP/ FU NDAP. São Paulo, (mimeo),1995.

AFFONSO, R. de B. Desigualdades regionais e desenvolvimento. Rui de Britto Affonso, Pedro Luiz Barros Silva (orgs.), São Paulo: FUND AP: Editora da Universidade Estadual de Paulista, (Federalismo no Brasil). 1995a.

AFO NSO, J. R. R. e SENRA, N. de C. "Despesa Pública. Competências, Serviços Locais, D escentralização: 0 Papel dos Municípios". Texto para Discussão, n. 23, CEPP. 1994. 
AFONSO, J. R. R. "A questão tributária e o financiamento dos diferentes níveis de governo" In: A Federação em Perspectivas: ensaios selecionados. Rui de Britto Álvares Affonso e Pedro Luiz Barros Silva (orgs). São Paulo: FU N DAP. 1995.

ANDRADE, Ilza A. Descentralização e Poder Municipal no Nordeste: os dois lados da nova moeda. Trabalho apresentado ao GT de Políticas Públicas do XX Encontro Nacional da Anpocs. Caxambu.1996.

AND RADE, Ilza A. Poder Municipal e Governabilidade. Textos para Discussão Base de Pesquisa: Estado e Políticas Públicas. Universidade Federal do Rio Grande do Norte. Natal. 1999.

ARRETCHE, M arta. "Políticas Sociais no Brasil: Descentralização em um Estado Federativo". Revista Brasileira de Ciências Sociais, v.14, n.40, p. 111-141. 1999.

ARRETCHE, M arta. Federalismo e Políticas Sociais no Brasil: problemas de coordenação e autonomia. Revista São Paulo em Perspectiva. São Paulo: v.18, n.2, p.17-26. 2004.

AVRITZER, L. e NAVARRO, Z. (orgs.). A inovação democrática no Brasil: o orçamento participativo. São Paulo: Cortez . 2003.

BAIO CCHI, G. Participation, Activism and Politics: The Porto Alegre Experiment and Deliberative Democratic Theory. Politics \& Society,29:1. 2001.

BOSCHI, R. Descentralização, clientelismo e capital social na governaça urbana: comparando Belo Horizonte e Salvador.Dados, Rio de Janeiro, v.42, n.4 p.655690. 1999.

BO UDO N, Raymond. "Theories of Social Change". U nited States by U niversity of California Press. 1986.

CARREIRÃO. Y. "Avaliação do Desempenho do Presidente e Voto. Q uem são os eleitores retrospectivos?", apresentado no XXIII Encontro Anual da ANPOCS Caxambu. 1999.

COELHO, V. e NOBRE, M. Participação e Deliberação: Teoria Democrática e Experiências Institucionais no Brasil Contemporâneo. São Paulo: Editora 34. 2004.

CÔ RTES, Soraya. "Fóruns participativos e governaça: uma sistematização das contribuições da literatura" In: Desenho institucional e participação política: experiências no Brasil contemporâneo, Rio de Janeiro: Vozes. 2005. 
Sociologias, Porto Alegre, ano 8, ํํ 16, jul/dez 2006, p. 86-125

COUTO, Cláudio. "O Processo Decisório Municipal como instrumento da Autonomia: considerações a partir do caso paulistano". In: MELO, Marcus André (org.). Reforma do Estado e mudança institucional no Brasil. Editora M assangana, p.285-306. Fundação Joaquim Nabuco, Recife. 1999

ELSTER, J. (org.). Rational choice. Nova York, New York U niversity Press. 1986.

FERN ANDES, A. Path dependency e os estudos históricos. BIB, São Paulo, n.53, p.79-112, 1을 semestre. 2002.

FERN ANDES A. "A agenda de gestão das capitais na década de 90: os casos de Recife e Salvador". Perspectivas - Revista de Ciências Sociais (U niversidade Estadual Paulista). São Paulo, 27: 83-107. 2005.

FIO RINA, Morris. Retrospective Voting. In: American National elections. New Haven, Yale University Press. 1981

FREY, Klauss. "Crise do Estado e Estilos de Gestão Municipal". In: Lua Nova Revista de Cultura Política, n.37. 1996

GOM ES, G. e MacD O WELL, M. C. "Elos Frágeis da Descentralização: O bservações sobre as finanças dos municípios brasileiros", (mimeo), IPEA, Braślia. 1995.

KRAM ER, Gerald H. Short-Term Fluctuations. In: U.S. Voting Behavior, 18961964. The American Political Science Review, 65(1): 131-143. 1971

LEW IS-BECK, Michael S. Economics and Elections: The Major Western Democracies.Ann Arbor: Michigan U niversity Press. 1988.

LIMO NGI, Fernando. 0 novo institucionalismo e os estudos legislativos: a literatura norte-americana recente. Boletim informativo e bibliográfico de Ciências Sociais. Rio de Janeiro, n.37, p. 3-38. 1994

LUBAMBO, Cátia. 0 Desempenho da Gestão Pública e seus Determinantes: uma análise em municípios do Nordeste. Recife, Universidade Federal de Pernambuco (Tese de doutorado). 2000.

LUBAM BO, C. W.; COELHO, D. B; MELO, M. A. (orgs.). Desenho Institucional e Participação Política: experiências no Brasil contemporâneo. 1.ed. Rio de Janeiro: Vozes, v. 1. 301 p. 2005.

MARQ UES, Eduardo. Redes Sociais e poder no Estado brasileiro: aprendizados a partir de políticas urbana. In: Revista Brasileira de Ciências Sociais, v.21. 2005 
MÉDICl, A. C. A Dinâmica do Gasto Social no Brasil nas Três Esferas de Governo: Uma Análise do Período 1980-1992. Relatório de Pesquisa. Subprojeto: Canais de Acesso aos Fundos Públicos na Área Social. Projeto: Balanço e Perspectivas do Federalismo Fiscal no Brasil. IESP/FUNDAP, junho de 1994.

MELO , M arcus And ré. Reformas Constitucionais no Brasil. Instituições políticas e processo decisório. Editora Revan, Rio de Janeiro. 2002.

PRZEW O RSKI, Adam.(1988)." Marxismo e Escolha Racional". In: Revista Brasileira de Ciências Sociais, 6:5-25. 1988.

REM MER, K. L. The Political Impact of Economic Crisis in Latin America in the 1980s. American Political Science Review, 85(3), p. 777-800. 1991.

REZENDE, Flávio. "Capacidade de Governo, Instituições e Descentraliação: um estudo empírico sobre governos locais no Brasil". In: Caderno de Estudos Sociais. Fundação Joaquim Nabuco.Recife. 1999.

SCHNEIDER, A. e GO LDFRANK, B. "Construção institucional competitiva: 0 PT e o O rçamento Participativo no Rio Grande do Sul". In: LUBAMBO, C. W.; COELHO, D. B; M ELO , M. A. (orgs.). Desenho Institucional e Participação Política: experiências no Brasil contemporâneo.Rio de Janeiro: Vozes, p. 221-255. 2005.

SERRA, José e AFO NSO, José R.. "As Finanças Públicas M unicipais: Trajetórias e Mitos". In: Conjuntura Econômica, Rio de Janeiro, v.45, n. 10 e 11, p.44-50. 1991.

SO UZA, Celina. Constitutional Engineering. In Brazil: The Politics of Federalism and Decentralization. N ew York: St.M artins's Press. 1997.

TEN DLER, Judith. Good government in the tropics. Baltimore and London. The Johns Hopkins U niversity Press. 1997.

TEN DLER,Judith.(1999). “Mitos da Reforma do Estado e a Descentralização: conclusões de um estudo de caso no Brasil" in Reforma do Estado e mudança institucional no Brasil. M ELO, M.A. (org.). Editora M assangana, pp.33-72. Fundação Joaquim Nabuco, Recife.

TUFTE, Edward R. Determinants of the O utcomes of Midterm Congressional Elections. American Political Science Review, 69(3), p. 812-826. 1975. 
Sociologias, Porto Alegre, ano 8, no 16, jul/dez 2006, p. 86-125

VEIGA, L. e MAGALHÂES, R.. "A construção da Preferência Eleitoral: o eleitor comum diante da campanha presidencial de 1998", apresentado no XXIII Encontro Anual da ANPOCS - Caxambu. 1999

W AM PLER, Brian. "Expandindo accountability através de instituições participativas? Ativistas e reformistas nas municipalidades brasileiras". In: Desenho institucional e participação política: experiências no Brasil contemporâneo. Rio de Janeiro: Vozes. 2005 
Sociologias, Porto Alegre, ano 8, № 16, jul/dez 2006, p. 86-125

\section{Resumo}

A análise da gestão pública desenvolvida neste estudo focaliza fatores explicativos associados ao desempenho dos governos em municípios de pequeno porte. As diferenças encontradas no desempenho da gestão pública em municípios, definidas por alguns fatores específicos que se procura desvendar, são reveladoras não só da variedade entre contextos e condicionalidades, como também da diversidade de constrangimentos que a descentralização encontra nos governos locais. No âmbito da literatura, alguns estudos sinalizam na direção de que fatores estruturais, como o desempenho fiscal dos governos, determinariam a possibilidade maior ou menor de sucesso de um dado governo local. Outros trabalhos apresentam fatores associados diretamente ao nível e natureza das demandas e a conseqüente forma de provisão social, como sendo fundamentais à aprovação ou não da gestão. O utros estudos ainda sugerem que as investigações prossigam na perspectiva das efetivas condições político-institucionais da implementação das políticas sociais no âmbito dos municípios. Diante da evidência de tantos fatores distintos que parecem importar para o desempenho da gestão municipal, é oportuno perguntar: existe uma correlação entre os atributos da gestão e a avaliação do seu desempenho? 0 trabalho analisa um universo de 75 municípios no Nordeste brasileiro, distribuídos entre os estados de Pernambuco, Rio Grande do Norte e Paraíba, durante a gestão 1993-1996. Discute e elege o Índice de Aprovação Popular como indicador do desempenho da gestão e investiga a influência de fatores específicos, supostamente explicativos desse desempenho. M ediante uma análise de "clusters", os resultados do estudo terminam por apontar semelhanças e diferenças entre grupos de municípios, com níveis distintos de desempenho da gestão, enfatizando a predominância de fatores associados à ação efetiva da gestão como determinantes da aprovação popular.

Palavras-chave: desempenho de governo, gestão pública e aprovação popular.

Recebido: 29/05/06

Aceite Final: 19/07/06 


\section{Public management performance: which variables are included in approval ratings in small towns?}

The analysis of public management carried out in this study focuses on explanatory elements associated to government performance in small towns. Differencesfound on public management performance in towns, defined according to some specific elements that we try to explain, reveal not only the variety of contexts and conditions but also the diversity of constraints that decentralization finds in local governments. In literature, some studies point out that structural elements such as government's tax performance would determine the higher or lower possibility for success of a given local government. O ther works present elements directly associated to the level and nature of demands and the resulting form of local provision as being crucial for approval or not of the administration. Yet other studies suggest that investigations proceed in the perspective of effective political-institutional conditions of implementation of social policies at municipal level. In face of evidence of so many distinct elements that seem to be relevant for the performance of the municipal management, we ask: is there any correlation between the administration's attributes and its approval ratings? This work examines a universe of 75 towns of Northeastern Brazil, distributed over the states of Pernambuco, Rio Grande do Norte, and Paraíba, during the 1993-1996 term. It discusses and elects the Approval Rating as the indicator of each administration's performance and it investigates the influence of specific factors, which allegedly explain such performance. After an analysis of "clusters", results of the study end up pointing out similarities and differences between groups of towns, with distinct levels of administration performance, stressing the prevalence of elements associated to the effective action of the administration as determinants for popular approval.

Key words: government performance, public administration, approval ratings. 